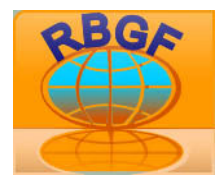

\title{
USO DO ÍNDICE DE VEGETAÇÃO DA DIFERENÇA NORMALIZADA (IVDN) PARA CARACTERIZAÇÃO DA COBERTURA VEGETAL DA REGIÃO DO ARARIPE PERNAMBUCANO
}

\author{
Ivan Ighour Silva Sá ${ }^{1}$; Josiclêda Domiciano Galvíncio ${ }^{2}$; Magna Soelma Beserra de Moura $^{3}$ e \\ Iêdo Bezerra Sá ${ }^{4}$
}

\section{RESUMO}

Artigo recebido em 08/09/2008 e aceito em 15/10/2008

O presente trabalho foi realizado para a região do Araripe, localizada no oeste de Pernambuco. Esta região apresenta importantes modificações em seu ambiente natural, principalmente ocasionadas pela remoção da cobertura vegetal nativa, muitas vezes resultante de desmatamento ilegal para a utilização da lenha como fonte energética nas indústrias gesseiras. Este trabalho buscou separar e quantificar a cobertura vegetal da região estudada a partir do Índice de Vegetação por Diferença Normalizada - IVDN estimado a partir de dados do sensor Landsat 5 TM, obtidos em 22 de janeiro de 2007. A fisionomia da vegetação de Contato entre Savana e Floresta Estacional que se encontra sobre a Chapada do Araripe foi quantificada em 1.010,54 km², enquanto a Savana Estépica Arborizada 2.125,33 $\mathrm{km}^{2}$ e a Florestada em $684,83 \mathrm{~km}^{2}$ que estão dispostas fora da Chapada. Observou-se que 3.118,32 $\mathrm{km}^{2}$ da região estudada encontram-se com algum grau de intervenção do homem. O município de Trindade é o que possui maior área coberta por remanescente (69\%), enquanto que Ouricuri a maior quantidade, qual seja $1.254,41 \mathrm{~km}^{2}$. Os municípios mais degradados são: Araripina e Bodocó, possuindo cerca de $51 \%$ de suas áreas antropizadas.

Palavras-chave: IVDN, ARARIPE, COBERTURA VEGETAL.

\section{VEGETATION DIFERENCE INDEX IN THE CARACTERIZATION OF THE VEGETABLE COVER IN THE AREA ARARIPE PERNAMBUCANO}

\begin{abstract}
The present work was accomplished for the area of Araripe located at the west of Pernambuco in the municipal districts of Araripina, Trinidade, Bodocó and Ouricuri. This area presents important modifications in its natural atmosphere, mainly caused by the removal of the covering resulting for the use of the firewood as energy source in the plater's industries. This work looked for to separate and to quantify the vegetable covering of the area studied starting from the Index of Vegetation by Normalized Difference - NDVI estimated starting from data of sensor TM of LANDSAT 5 obtained on January 22, 2007. The physiognomy of the vegetation of Contact among Savanna and Seasonal Forest that it meets on it Plated of Araripe it was quantified in $1010,54 \mathrm{~km}^{2}$, while the Estepic Savanna $2125,33 \mathrm{~km}^{2}$ and Forested Savanna in $684,83 \mathrm{~km}^{2}$ that are out arranged of the Plated. It was observed $3118,32 \mathrm{~km}^{2}$ of the studied area it also meets with some degree of the man's intervention. The Trindade municipal district is what possesses larger covered area for remainder $(69 \%)$ while Ouricuri the largest amount $1254,41 \mathrm{~km}^{2}$. The degraded municipal districts are the one of Araripina and Bodoco possessing about $51 \%$ of its areas with use of the human.

Keywords: NDVI, ARARIPE, VEGETABLE COVERING

\footnotetext{
${ }^{1}$ Mestrando em Geografia pela Universidade Federal de Pernambuco - e-mail: ighour@hotmail.com; Avenida Professor Morais Rego, s/n. Cidade Universitária, Recife-PE

${ }^{2}$ Professora do Departamento de Geografia da Universidade Federal de Pernambuco. E-mail: josicleda@hotmail.com

${ }^{3}$ Pesquisadora da Embrapa Semi-Árido - e-mail: magna@cpatsa.embrapa.br

${ }^{4}$ Pesquisador da Embrapa Semi-árido - e-mail: iedo@cpatsa.embrapa.br
} 


\section{INTRODUÇÃO}

No extremo oeste pernambucano está localizada a região que possui a maior reserva de gipsita do Brasil e a segunda maior do mundo. Este mineral, a partir de um processo de desidratação, se transforma em gesso, material que está sendo amplamente utilizado nas obras de engenharia.

Os principais produtores de gesso são os municípios de Araripina, Trindade, Ipubi, Bodocó e Ouricuri, que formam o pólo gesseiro da região do Araripe pernambucano, responsável por $95 \%$ da produção nacional e pela geração de milhares de empregos diretos e indiretos nas mineradoras, calcinadoras e fabricas de pré-moldados instaladas na região (SINDUSGESSO, 1999). Entre 1999 e 2004 o volume de produção de gesso no pólo cresceu $33 \%$, totalizando 3,6 milhões de toneladas de gesso, pré-moldados e gipsita. O pólo gesseiro do Estado de Pernambuco é considerado um Arranjo Produtivo Local (APL) em nível estadual e federal, possuindo uma reserva estimada em 1,2 bilhão de toneladas e perspectiva de exploração por mais 30 anos (EMBRAPA, 2006).

A região do Araripe apresenta importantes modificações em seu ambiente natural, principalmente ocasionadas pela remoção da cobertura vegetal nativa, muitas vezes resultante de desmatamento ilegal para a utilização da lenha como fonte energética nas indústrias gesseiras. Portanto, as atividades econômicas do pólo gesseiro do Araripe têm relação intrínseca com a problemática ambiental causada pela remoção de cobertura vegetal nativa - caatinga.

A comunidade científica tem buscado formas para realização do monitoramento, avaliação e inventário da paisagem. Dentre os métodos utilizados, a avaliação das informações obtidas por meio de sensoriamento remoto, tem gerado dados que são amplamente utilizados nesses estudos. Essas pesquisas têm demonstrado resultados satisfatórios na obtenção de informações, tanto pela precisão dos resultados, como pela agilidade na obtenção dos dados, não obstante ao custo inferior quando comparado com métodos convencionais. TEOTIA et al. (2001), ao empregarem imagens do sensor HRV (High Resolution Visible) do satélite SPOT (Satellite pour l'Observation de la Terre ) para realização de estudos temáticos sobre o uso da terra/cobertura vegetal e a classificação do solo na região semi-árida do Estado do Piauí, mais precisamente, nos municípios de Jaicós e Picos, obtiveram um banco de dados, que foi a informação básica para geração de um mapa de aptidão das terras para fins de planejamento e desenvolvimento rural.

FERREIRA et al. (2001) utilizaram imagens temporais do sensor TM - Landsat para o município de Patos - PB, onde ocorrem ações desordenadas de degradação da cobertura vegetal natural. Estes pesquisadores definiram três estratos representativos de caatinga e concluíram que a cobertura vegetal 


\section{RBGF - Revista Brasileira de Geografia Física \\ Recife-PE Vol. 01 n.01 Mai/Ago 2008, 28-38}

desse município é constituída, basicamente, por vegetação arbustiva-arbórea fechada. MALDONADO et al. (2001) realizaram estudo na área do município de Quixaba, Pernambuco, utilizando técnica dos componentes principais em imagens temporais do TM - Landsat 5 e rotação espectral controlada para mostrar a viabilidade dessa ferramenta em estudos de detecção de mudanças de uso e cobertura da terra, observando que esta metodologia pode ser utilizada na detecção e conseqüentemente a definição do tipo de mudança registrada, degradação ou recuperação da paisagem.

Este estudo pretende determinar a situação atual da cobertura vegetal da região Araripe Pernambuco, mediante uso do Índice de Vegetação da Diferença Normalizada.

\section{MATERIAL E MÉTODOS}

\subsection{Caracterização da área de estudo}

Este estudo foi realizado nos municípios de Araripina, Bodocó, Ouricuri, Trindade e Ipubi, no Estado de Pernambuco, que formam o pólo gesseiro do Araripe Pernambucano, totalizando $7.082,86 \mathrm{~km}^{2}$, que representam 7,20\% da área total do Estado de Pernambuco. O município de Ouricuri é o maior deles e ocupa $33,55 \%$ da região estudada

A região de estudo está contida no Bioma Caatinga, e segundo Giulietti et al. (2004) é uma área de extrema importância biológica com necessidade de conservação da sua flora, pois se trata de uma região de mosaicos vegetacionais.

A Caatinga é classificada pelo IBGE como Savana Estépica. Este termo foi empregado no Brasil para designar a área do "sertão árido nordestino" com dupla estacionalidade, possuindo dois períodos secos anuais, um com longo déficit hídrico seguido de chuvas intermitentes e outro com seca curta, seguido de chuvas torrenciais que podem faltar durante anos (IBGE, 1992).

Sá et al. (2007), estudando o potencial florestal da região do Araripe pernambucano, demonstraram que a mesma possui três fisionomias florestais distintas. Nas áreas com altitudes que variam entre 359 a 625 metros, é encontrada a fisionomia Savana Estépica Florestada (Td). Este Subgrupo de formação é caracterizado por micro e/ou nanofanerófitos, onde as plantas apresentam altura média de 5 $\mathrm{m}$, excepcionalmente ultrapassando os $7 \mathrm{~m}$ de altura, mais ou menos densos, com troncos grossos e esgalhamento bastante ramificado, em geral, provido de espinhos e/ou acúleos, com total decidualidade na época desfavorável (IBGE, 1992). Outra fisionomia que ocorre nessa região é a Savana Estépica Arborizada (Ta). Esta fisionomia apresenta as mesmas características florísticas da fisionomia ecológica citada anteriormente; porém, os indivíduos que a compõem são mais baixos, existindo clareira entre eles. O terceiro grupo ocorre na parte mais elevada, que corresponde à parte da Chapada do Araripe com as áreas de 
encraves vegetacionais de Savana (cerrado), Savana Estépica (caatinga) e Floresta Estacional (STN), não podendo ter suas fisionomias diferenciadas com imagens de satélite de baixa resolução (IBGE, 1992).

As áreas com fisionomias degradadas neste trabalho foram tratadas como regiões que sofreram alguma intervenção antrópica, e foram interpretadas, visualmente, pela textura e padrão na imagem de satélite analisada.

De acordo com o Zoneamento Agroecológico do Estado de Pernambuco, realizado na escala de 1:100.000 (ZANE, 2002), existem na região do Araripe 9 classes de solos: Neossolo Flúvico, cambissolo háplico, latossolo amarelo, luvissolo crômico, argissolo amarelo, argissolo solódico, argissolo vermelho-amarelo, neossolo litólico e vertissolos, distribuídos nos cinco municípios.

A partir de dados pluviométricos obtidos em postos da SUDENE, pode-se observar que a região de estudo apresenta período chuvoso compreendido entre novembro e agosto, com os maiores índices de pluviosidade registrados entre os meses de janeiro e março. Com as coordenadas geográficas desses postos, foram estimados os dados mensais da temperatura do ar média, segundo metodologia proposta por CAVALCANTI \& SILVA

demonstrando que a região possui temperatura média anual variando entre 23 e $27^{\circ} \mathrm{C}$.

\subsection{Processamento digital das imagens}

Sá, I. I. S.; Galvíncio, J. D. Moura M. S. B. de.; Sá, I. B.
Foram utilizadas imagens digitais do sensor Thematic Mapper (TM) do satélite Landsat 5, obtidas na órbita 217 e pontos 65 e 66, em 22/01/2007. Uma base digital de rodovias da região, elaborada a partir de levantamento de campo com equipamento de sistema de posicionamento global (GPS), foi utilizada para realizar a correção geométrica. Para o processamento das imagens digitais utilizou-se software de sistemas de informações geográficas (SIG).

As imagens da órbita 217 e pontos 65 e 66, adquiridas em 22/01/2007, foram obtidas no site de geração de imagens do INPE em formato geotiff com projeção/datum UTM/SAD-69. O ângulo de elevação solar do ponto 65 era de $56,83^{\circ}$ e do ponto 66 é $57,24^{\circ}$, porém o valor utilizado foi uma média aritmética $(57,03)$ do ângulo de elevação do Sol destes dois pontos, por a área de estudo compreender a área de intersecção das duas imagens. É de grande importância ressaltar que este satélite possui uma resolução espacial de 30x30 metros cobrindo cada pixel $900 \mathrm{~m}^{2}$, resolução temporal de 16 dias e radiométrica de 8 bits.

O primeiro processamento foi a fusão das sete bandas de cada imagem com posterior mosaicagem e segmentação da imagem para a região de estudo utilizando a malha municipal digital do IBGE.

No processo de correção geométrica (registro) foi utilizado o método polinomial de primeira ordem para ajustar a imagem com a 


\section{RBGF - Revista Brasileira de Geografia Física \\ Recife-PE Vol. 01 n.01 Mai/Ago 2008, 28-38}

realidade do campo no sentido de se fazer levantamentos futuros acerca da estrutura florestal para as classes levantadas.

A retificação radiométrica foi feita a partir da conversão dos números digitais em radiância e posteriormente em reflectância utilizando as equações 1 e 2 , quais sejam (Bastiaansen, 2000):

$$
L \lambda=N D . \frac{L \max -L \min }{255}+L \min
$$

onde $L \lambda$ é a radiância de cada banda $\left(\mathrm{W} \mathrm{m}^{-2}\right.$ $\left.\mathrm{sr}^{-1} \mu \mathrm{m}^{-1}\right)$, ND o valor do número digital do pixel na banda $\lambda$ e Lmax e Lmin são as radiâncias máxima e mínima expressas em $\mathrm{W}$ $\mathrm{m}^{-2} \mathrm{sr}^{-1} \mu \mathrm{m}^{-1}$ para o sensor e banda em questão.

$\rho \lambda=\frac{\pi \cdot L \lambda \cdot d^{2}}{E S o l \lambda \cdot \operatorname{Cos} \theta s}$

onde $\rho \lambda$ é a reflectância planetária ao nível de satélite para cada banda, $\pi \mathrm{L}$ é a radiação total refletida por cada pixel, resultante da integração hemisférica da radiação $\mathrm{L} \lambda$ (em W $\left.\mathrm{m}^{-2} \cdot \mu \mathrm{m}^{-1}\right), \mathrm{d}$ é a distância do Sol à terra em unidades astronômicas, ESol入 é a irradiância solar média espectral no topo da atmosfera (W $\left.\mathrm{m}^{-2} \mu \mathrm{m}^{-1}\right)$ e $\theta \mathrm{s}$ é o ângulo zenital solar, admitido constante para cada pixel da imagem e obtido a partir do ângulo de elevação do Sol, dado no cabeçalho de cada imagem selecionada.

A partir dos dados de reflectância foi calculado, através da equação 3 , o índice de vegetação da diferença normalizada (IVDN) proposto por Rouse et al. (1974). Os valores do IVDN variam entre -1 e 1. Nas áreas com vegetação o IVDN, geralmente, varia entre 0,1 e 0,8 , conforme a sua arquitetura, densidade e umidade. Rochas e solos sem vegetação apresentam valores próximos a zero e água apresenta valores negativos (Holben, 1986; Justice et al., 1985).

$I V D N=\frac{\rho 4-\rho 3}{\rho 4+\rho 3}$

onde $\rho 4$ e $\rho 3$ são as reflectâncias planetárias ao nível dos satélites Landsat 5 e 7, para as banda 4 e 3 , respectivamente.

Após a obtenção da imagem IVDN foi feita uma classificação não supervisionada procurando a diferenciação e a quantificação das fisionomias a partir deste índice. Também foi utilizado um conjunto de 19 pixels de cada classe mapeada para se obter as variáveis estatísticas do IVDN para cada dossel analisado.

\section{RESULTADOS E DISCUSSÃO}

A Figura 1 apresenta a precipitação observada durante o período de 22 de outubro de 2006 até 28 de janeiro de 2007. Ambos os municípios receberam quantidades de chuvas semelhantes até o dia 10 de janeiro de 2007, e desta data até o 14 de janeiro de 2007 a precipitação foi significativa nos municípios de Araripina, Ipubi e Bodocó. O acumulado de precipitação de outubro de 2006 a 22 de janeiro de 2007 foi de 85,7 mm em Araripina, $87,6 \mathrm{~mm}$ em Ipubi, 58,4 mm em Bodocó, e $50,5 \mathrm{~mm}$ em Ouricuri. 


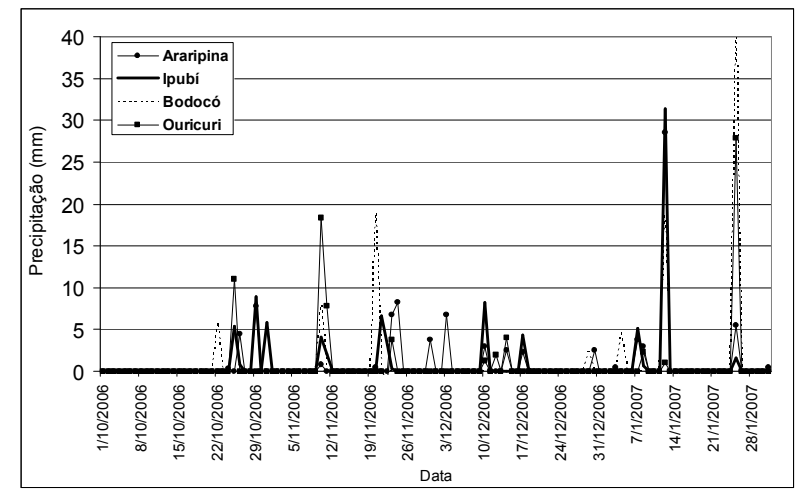

Figura 1. Precipitação registrada na região do Araripe Pernambucano entre o período de 01/10/2006 e 28/01/2007. Fonte: LAMEPE Laboratório de Meteorologia de Pernambuco

\section{A distribuição das fisionomias} existentes na área de estudo, o local da coleta dos pixels de referência utilizados na análise para a diferenciação das fisionomias, e as classes de solos encontram-se representados nas Figuras 1 (a e b).

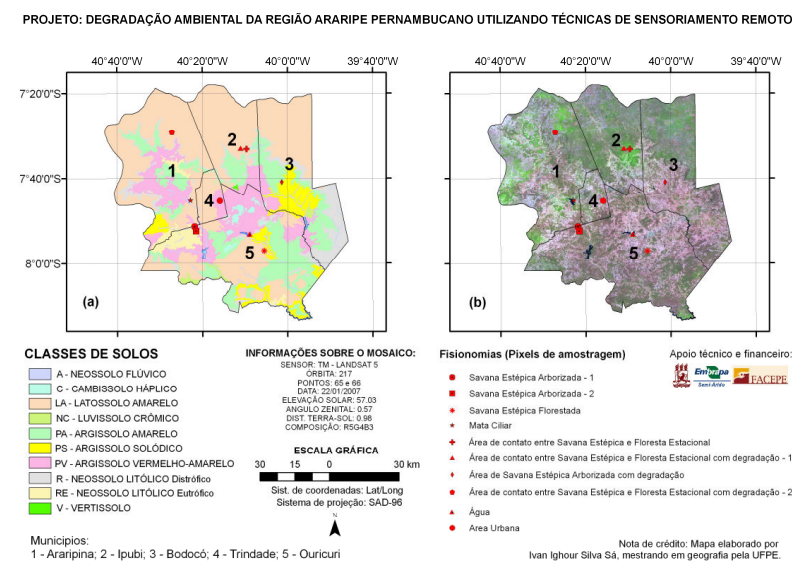

FIGURA 1 - (a) classes de solos existentes na área de estudo; (b) Composição colorida, pixels de referências da área de estudo.

Os valores médios e desvio padrão do IVDN estimados na área de estudo utilizando um conjunto de 19 pixels foram: 0,5779 $( \pm$ 0,0662) na área de Mata Ciliar sobre o Latossolo Amarelo; 0,3602 ( \pm 0,0170) para área de Savana Estépica Arborizada sobre o Neossolo Litólico e 0,3870 ( $\pm 0,014)$ sobre o Argissolo Amarelo; 0,4393 ( \pm 0,0153) na área de Savana Estépica Florestada com Latossolo amarelo; 0,6679 $( \pm 0,0184)$ nas áreas de contato entre vegetação do tipo Savana e Floresta Estacional, também sobre o Latossolo Amarelo; 0,3332 ( \pm 0,0056) e 0,2058 \pm 0,0268) nas áreas de contato entre Savana Estépica e Floresta Estacional que estão com algum grau de intervenção antrópica e sobre o solo do tipo Latossolo Amarelo; 0,2556 ( 0,0193) em área de Savana Estépica arborizada degradada com Latossolo amarelo e $0,2330( \pm 0,0492)$ na área de influência urbana.

O valor mínimo do IVDN para toda a área de estudo foi de - 0,7400 e o máximo 0,7960 ; o médio 0,2820 ; a mediana 0,2620 ; a moda 0,1542 e o desvio padrão 0,1240 . ESPIG et al. (2008), estudando variações sazonais na vegetação de caatinga em seis áreas do SemiÁrido nordestino utilizando dados do MODIS, estimaram os valores mínimos destas em 0,22 ; 0,$10 ; 0,22 ; 0,09 ; 0,11$ e 0,21 ; os valores médios em 0,$48 ; 0,40 ; 0,37 ; 0,43 ; 0,44 ; 0,37$; e os valores máximos em 0,$87 ; 0,78 ; 0,63 ; 0,69$; 0,$76 ; 0,66$.

A classificação não-supervisionada utilizando 14 classes para separação das fisionomias florestais da região de estudo 
resultou nos valores de IVDN conforme a Figura 2.

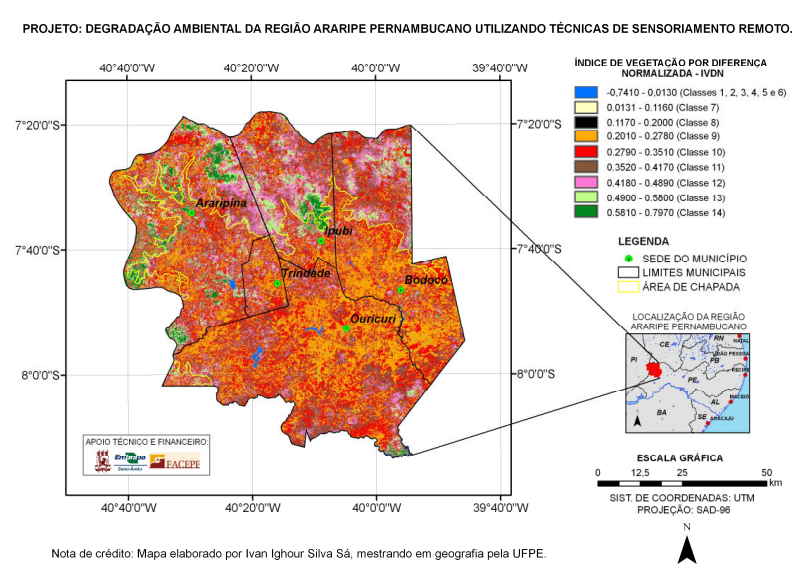

FIGURA 2 - Mapa do IVDN na região de estudo.

Nas áreas de Savana Estépica Arborizada e Florestada que se encontram degradada, o IVDN variou entre 0,201 e 0,278 (cor laranja/classe-9). Já nas áreas de Contato de Savana e Floresta Estacional este índice também variou entre 0,201 e 0,278 (cor laranja/classe-9), mas também foi encontrado através de interpretação visual, degradação nas áreas com índice estimado entre 0,279 e 0,351 (cor vermelho/classe-10). Nas áreas de Mata Ciliar o IVDN variou entre 0,490 - 0,580 (cor verde claro) e 0,581 a 0,797 (cor verde escuro) podendo ser facilmente separadas, pois são encontradas próximas aos corpos hídricos. A classificação separou os solos expostos na classe 7 (0,0131 a 0,1160/cor amarela) e classe $8(0,1170$ a $0,2000 /$ cor preta $)$ variou de solo exposto a vegetação rala. Neste trabalho os valores negativos de IVDN, desde - 0,7410 a 0,0835 (classes 1, 2, 3, 4, 5 ) foram atribuídos aos corpos hídricos profundos e limpos e 0,0834 à 0,1130 (classe 6) aos rasos e com sedimentos.

A quantificação das fisionomias existentes fica comprometida quando se analisa os valores de IVDN para toda a região de estudo, uma vez que a região apresenta variações climáticas que interferem no comportamento espectral da vegetação. Assim, áreas com baixa cobertura vegetal, devido ao estresse hídrico, podem apresentar índices de vegetação semelhantes a áreas exploradas, mas que estejam influenciadas por ocorrência de precipitação. Por exemplo, as áreas de Savana Estépica Arborizada de Ouricuri apresentaram IVDN semelhantes a algumas áreas de Contato localizadas na Chapada do Araripe que foram exploradas, indicando que esta exploração pode ter sido feita por corte seletivo de madeira ou que a área já se encontra em estágio de regeneração. Levantados todos estes aspectos, a alternativa deste trabalho para quantificar as fisionomias e minimizar os erros foi a segmentação da imagem do IVDN por municípios, separando a área de chapada das demais, no intuito de diminuir as interferências climáticas na cobertura vegetal. Ainda, obtevese então a ocupação da Chapada do Araripe por municípios, onde a mesma ocupa cerca de 51,47\% do território de Araripina, 39,96\% em Bodocó, 75,80\% em Ipubí, 2,35\% em Ibupi, e $0,49 \%$ em Trindade. A quantificação das fisionomias após ponderação das classes analisadas encontram-se representadas na 
Tabela 1 (em anexo).

Através do IVDN pode-se observar que a região do Araripe Pernambucano possui aproximadamente $54 \%$ de cobertura vegetal remanescente distribuídas entre as fisionomias Savana Estépica Arborizada, Florestada e áreas de contato entre Savana e Floresta Estacional, $30 \%, 10 \%$ e $14 \%$, respectivamente. As áreas antropizadas ocupam cerca de $44 \%$ em diferentes níveis que não foram analisados neste trabalho. Os recursos hídricos superficiais representam $0,32 \%$ da área. Sá et al. (2007) através de mapeamento utilizando a técnica em sensoriamento remoto de interpretação visual com imagens de 2002, estimou que 39\% da área está sob intervenção antrópica e 22,16\% para as áreas de Savana Estépica Arborizada. Essa diferença de 5\% ocorre devido as diferenças climáticas uma vez que a imagem utilizada por Sá et al. (2007) foi do mês de maio, final do período chuvoso e a imagem aqui utilizada é do inicio do período chuvoso, janeiro. Albuquerque et al., (2007) avaliando as influências da precipitação na cobertura vegetal de regiões semi-áridas de Pernambuco obteve que a cobertura da terra varia em torno de $15 \%$ da época seca para a época chuvosa, resultado semelhante ao obtido neste estudo.

Proporcionalmente, o município que possui maior área coberta por remanescentes de vegetação é Trindade com aproximadamente $69 \%$ da área, porém o que tem maior quantidade de remanescente é o município de Ouricuri que possui 1494,31 km² coberto por vegetação que ainda não foi explorada ou se encontram próximas ao estágio clímax de sucessão ecológica. Os municípios mais degradados são os de Araripina e Bodocó possuindo cerca de 51\% de suas áreas antropizadas.

Por todos estes aspectos é satisfatória a contribuição do IVDN na avaliação da cobertura vegetal da região do Araripe, podendo ser utilizado no monitoramento ambiental. O levantamento da estrutura florestal (horizontal e vertical) in loco para correlacionar os dados de campo com os processados digitalmente dariam a análise realizada neste trabalho uma maior precisão e qualidade nas avaliações. Ressalta-se a necessidade de um programa adequado de manejo da cobertura vegetal bem como intervenção nas regiões degradadas de modo a se recuperar essas áreas para que se possa conseguir uma produtividade sustentada, que pode ser contemplada a partir de planos de manejos florestais.

\section{CONCLUSÕES}

- A divisão do IVDN em 14 classes foi satisfatória na separação das fisionomias existentes na região estudada, com a ressalva da necessidade de se separar a vegetação da Chapada das áreas mais baixas, uma vez que são influenciadas por variações climáticas. 
- A região possui cerca de $44 \%$ de áreas degradadas e $54 \%$ de remanescentes de vegetação passíveis de exploração, que deve ser realizada de forma sustentada para que garanta a auto-suficiência de matriz energética.

\section{AGRADECIMENTOS}

Os autores deste trabalho agradecem a Fundação de Amparo a Ciência do Estado de Pernambuco (FACEPE) pelo apoio a bolsa de estudo e ao CNPq pelo apoio financeiro.

\section{REFERÊNCIAS}

Albuquerque, F. J. A. de.; Pimentel Neto, J. G.; Galvíncio, J. D. Análise da cobertura da terra em função da precipitação mensal (janeiro $\mathrm{e}$ outubro) utilizando imagens CBERS para o município de Ouricuri-PE. Revista de Geografia. Recife: UFPE-DCG/NAPA, pp.0718, v.24, $\mathrm{n}^{0} 01, \mathrm{jan} / \mathrm{abr}, 2007$.

Bastiaanssen, W. G. M. SEBAL - based sensible and latent heat fluxes in the irrigated Gediz Basin, Turkey. Journal of Hydrology, v.229, p.87-100, 2000.

Costa, T.C.C.; Accioly, L.J.O.; Oliveira, M.A.J.; Burgos, N.; Silva, F.H.B.B. Mapeamento da fitomassa da caatinga do Núcleo de Desertificação do Seridó, pelo índice de área de planta (IAP) e o índice de vegetação da diferença normalizada (NDVI), obtido com dados do sensor Landsat 7 TM. In: Simpósio Brasileiro de Sensoriamento Remoto, 10. Foz do Iguaçu, Paraná. Abril, 2001. Anais. São José dos Campos:INPE, 2001. [CDROM].

CAVALCANTI, E.P.; SILVA, E.D.V. Estimativa da temperatura do ar em função das coordenadas locais. In: Congresso Brasileiro de Meteorologia, 7, e Congresso Latino-
Americano e Ibérico de Meteorologia, 1994, Belo Horizonte. Anais..., Belo Horizonte: Sociedade Brasileira de Meteorologia, 1994, p.154-157.

EMBRAPA (EMPRESA BRASILEIRA DE PESQUISA AGROPECUÁRIA). Aumento da Oferta de Matéria-Prima de Base Florestal Sustentável para o Desenvolvimento SócioEconômico da Região do Araripe. Centro de Pesquisa Agropecuária do Trópico SemiÁrido. Drumond, M.A. Recursos Florestais/Agroenergia. Petrolina, Brasil, 2000

ESPIG, S. A., SOARES, J. V., SANTOS, J. R. dos. VARIAÇÕES SAZONAIS DO EVI E NDVI EM ÁREAS DO SEMI-ÁRIDO BRASILEIRO. In: VIII Seminário em Atualização em Senoriamento Remoto e Sistemas de Informações Geográficas Aplicados à Engenharia Florestal, 2008. Curitiba. Anais do VIII Seminário em Atualização em Senoriamento Remoto e Sistemas de Informações Geográficas Aplicados à Engenharia Florestal, 2008. v. único. p. 219-226.

Ferreira, L. A., Teotia, H.S., Costa Filho, J. F., Santos, J. R. Levantamento e Classificação da vegetação nativa do município de Patos, através do sensoriamento remoto $\mathrm{e}$ geoprocessamento. In: Simpósio Brasileiro de Sensoriamento Remoto, 10. Foz do Iguaçu, Paraná. Abril, 2001. Anais. São José dos Campos:INPE, 2001. [CDROM].

HOLBEN, B. N. (1986). Characterization of maximum value composites from temporal AVHRR data. International Journal of Remote Sensing, 7, 1417- 1434.

Giulietti, A.M., et al. 2004. Diagnóstico da vegetação nativa do bioma Caatinga. In: J.M.C. Silva, M. Tabarelli, M.T. Fonseca \& L.V. Lins (orgs.). Biodiversidade da Caatinga: áreas e ações prioritárias para a conservação. pp. 48-90. Ministério do Meio Ambiente, Brasília.

IBGE. Manual Técnico da Vegetação Brasileira. Série Manuais Téenicos em 
Geociências, n¹. Rio de Janeiro, IBGE, 1992.

JUSTICE， C.O.; TOWNSHEND， J.R.G.; HOLBEN, B.N.; TURCKER, C.J. Analysis of the phenology of global vegetation using meteorological satellite data. International Journal of Remote Sensing, 6(8): 1271- 1318, Aug. 1985.

Maldonado, F.D.; Santos, J.R.; Carvalho, V.C. Rotação espectral controlada como alternativa em análise por componentes principais para detecção de mudanças em região do semiárido. Anais XI SBSR, Belo Horizonte, Brasil, 05 - 10 abril 2003, INPE, p. 1969 - 1976.1975 In: Simpósio Brasileiro de Sensoriamento Remoto, 10. Foz do Iguaçu, Paraná. Abril, 2001. Anais. São José dos Campos:INPE, 2001. [CDROM].

ROUSE, J.W.; HAAS JR., R..H.; DEERING, D.W.; SCHELL, J. A.; HARLAN, J. C. Monitoring the vernal advancement and retrogradation (green wave effect) of natural vegetation, NASA/GSFC type III final report: Greenbelt, Maryland, NASA, 1974, $371 \mathrm{p}$.

SÁ, I. B., SÁ, I. I. S., SILVA, F. D.. Geotecnologias conciliando preservação ambiental e fortalecimento das atividades produtivas na região do Araripe-PE. In: Simpósio Brasileiro de Sensoriamento Remoto, 13. Florianópolis, Santa Catarina. Abril, 2007. Anais. São José dos Campos: INPE, 2007. [CDROM].

SINDUSGESSO (SINDICATO DAS INDÚSTRIAS DO GESSO DE PERNAMBUCO). O Pólo Gesseiro. Recife, Brasil, 1999.

Teotia ,H.S., Costa Filho, J.F., Santos, J.R., Ferreira,.L.A. Integração do Sensoriamento Remoto e SIG/SIT na preparação de modelo de desenvolvimento da terra para planejamento rural. In: Simpósio Brasileiro de Sensoriamento Remoto, 10. Foz de Iguaçu, Paraná. Abril, 2001. Anais. São José dos Campos: INPE, 2001. [CDROM].
EMBRAPA. Zoneamento Agroecológico de Pernambuco - ZAPE. Recife, Embrapa Solos - UEP Recife. Il. 1CD Rom. 2004. 


\section{RBGF - Revista Brasileira de Geografia Física}

Recife-PE Vol. 01 n.01 Mai/Ago 2008, 28-38

Tabela-1. Quantificação dos recursos florestais da região Araripe Pernambucano. Onde: Ta Savana Estépica Arborizada; Td - Savana Estépica Florestada; SN - Áreas de contato entre Savana e Floresta Estacional.

\section{Fisionomia (área $\mathbf{k m}^{2}$ )}

\begin{tabular}{ccccccc} 
Município & Ta & Td & SN & $\begin{array}{c}\text { Ações } \\
\text { antrópicas }\end{array}$ & $\begin{array}{c}\text { Recursos } \\
\text { Hídricos }\end{array}$ & $\begin{array}{c}\text { Solos } \\
\text { Exposto }\end{array}$ \\
\hline Araripina & 187,21 & 292,40 & 405,21 & 976,74 & 4,62 & 42,33 \\
Bodocó & 454,46 & 66,94 & 236,66 & 813,13 & 1,97 & 24,95 \\
Trindade & 116,90 & 42,44 & 0,31 & 67,62 & - & 1,97 \\
Iipubí & 112,35 & 66,85 & 344,66 & 429,97 & 0,09 & 16,43 \\
Ouricuri & 1254,41 & 216,20 & 23,70 & 830,86 & 16,58 & 32,96 \\
\hline Total & $\mathbf{2 1 2 5 , 3 3}$ & $\mathbf{6 8 4 , 8 3}$ & $\mathbf{1 0 1 0 , 5 4}$ & $\mathbf{3 1 1 8 , 3 2}$ & $\mathbf{2 3 , 2 6}$ & $\mathbf{1 1 8 , 6 4}$
\end{tabular}

